\title{
Thinking About the Future Moves Attention to the Right
}

\author{
Marc Ouellet, Julio Santiago, María Jesús Funes, and Juan Lupiáñez \\ Universidad de Granada
}

\begin{abstract}
Previous studies have shown that past and future temporal concepts are spatially represented (past being located to the left and future to the right in a mental time line). This study aims at further investigating the nature of this space-time conceptual metaphor, by testing whether the temporal reference of words orient spatial attention or rather prime a congruent left/right response. A modified version of the spatial cuing paradigm was used in which a word's temporal reference must be kept in working memory whilst participants carry out a spatial localization (Experiment 1) or a direction discrimination, spatial Stroop task (Experiment 2). The results showed that the mere activation of the past or future concepts both oriented attention and primed motor responses to left or right space, respectively, and these effects were independent. Moreover, in spite of the fact that such time-reference cues were nonpredictive, the use of a short and a long stimulus onset asynchrony in Experiment 3 showed that these cues modulated spatial attention as typical central cues like arrows do, suggesting a common mechanism for these two types of cuing.
\end{abstract}

Keywords: conceptual metaphor, attentional orienting, time, semantics, embodied cognition

How do we represent abstract concepts? Do they need a concrete grounding to sustain the abstraction they refer to? Findings from linguistic studies suggest that they do (Lakoff \& Johnson, 1980, 1999; Johnson, 1987). As an example, think of the concept of time and how it would be possible to represent past and future. Everyday expressions of time in possibly all languages (Haspelmath, 1997; Radden, 2004) show how this abstract concept is naturally associated with the more concrete concept of space. In English, Spanish, and many other languages, a back-front spatial metaphor is often used, which maps past to locations in the back, future to locations in front, and time passing to forward movement (e.g. "Serbia plunges back into the past," title from an article of the Inter Press Service News Agency, or "Looking forward to seeing you," in a common letter).

However, linguistic analysis alone is limited to the metaphors manifested in language, which may not be the only ones available (Casasanto, 2009). Empirical data from Torralbo, Santiago, \&

Marc Ouellet, Julio Santiago, María Jesús Funes, and Juan Lupiáñez, Dept. de Psicología Experimental y Fisiología del Comportamiento, Universidad de Granada.

The present research was carried out as partial fulfillment of the requirements for Marc Ouellet's PhD thesis at the Doctorate Program on Psicología Experimental y Neurociencias del Comportamiento, Dept. de Psicología Experimental y Fisiología del Comportamiento, Universidad de Granada, under the supervision of Julio Santiago. Financial support came from a Researcher's Training Grant, Programa de Formación de Doctores en Centros de Investigación y Universidades Andaluzas, Consejería de Innovación, Ciencia y Empresa de la Junta de Andalucía, to Marc Ouellet, and from grant SEJ2006-04732/PSIC, funded by DGI, Ministerio de Educación y Ciencia, Plan Nacional de Investigación Científica, Desarrollo e Innovación Tecnológica (I + D + i), 2006-2009, to Julio Santiago (PI).

Correspondence concerning this article should be addressed to Marc Ouellet, Dept. de Psicología Experimental y Fisiología del Comportamiento, Universidad de Granada, Facultad de Psicología, Campus de Cartuja, 18071-Granada, Spain. E-mail: mouellet@ugr.es
Lupiáñez (2006, exp. 1) support, on one hand, the projection of time onto a back-front spatial frame, as previously reported in linguistic literature (Lakoff \& Johnson, 1980, 1999; Johnson, 1987). Participants were asked to judge if a word appearing to the front or the back of a side-looking head silhouette referred to the past or to the future. Words were conjugated verbs and temporal adverbs, and word location was completely orthogonal to word temporal meaning. However, participants were faster to respond when past words were presented to the back of the head and future words were presented to the front.

On the other hand, Torralbo et al (2006, exp. 2) also showed in the same study that when participants are asked to give a left-right manual response, they activate a left-past right-future representation of time. This mapping, although never found in linguistic expressions of any oral language (Radden, 2004), overruled the back-front mapping when manual responses were used. In another study, Santiago, Lupiáñez, Pérez, \& Funes (2007) investigated directly this horizontal left-right representation of time. They found a facilitation effect when past words were presented on the left side of the screen or responded to with the left hand. The opposite was true for future words. Recently, Santiago, Román, Ouellet, Rodríguez, \& Pérez-Azor (2008) extended this left-right space-time congruency effect to meaningful event sequences presented by means of movie clips or picture sequences. Again, order judgments between two events were faster when the left hand was used to respond "before" and the right hand to respond "after" than with the opposite mapping. These data are consistent with the observation that people gesture from left to right when describing events that unfold in time (Núñez \& Sweetser, 2006), and also with data from an off-line task asking participants to place stickers on a paper to represent events such as breakfast, lunch and dinner (Tversky, Kugelmass, \& Winter, 1991). The latter study also found evidence suggesting that this horizontal mapping of time might be related to the habitual direction of reading and writing.

The left-right space-time congruency effect could be accounted for in, at least, two different ways. It could be that temporal 
meanings direct spatial attention, or alternatively, that they are associated with left/right manual response codes (or both), leading to the automatic activation of congruent reactions. The main goal of the present paper is to discriminate between these two alternative underlying mechanisms.

In order to do this, we devised a variation of the widely used cuing paradigm to study attentional orienting (Posner, 1980; Posner \& Cohen, 1984; Posner, Nissen \& Ogden, 1978). In a cuing paradigm, a spatial cue is used to prime a region of the visual field, and its effects are measured on the processing of a target appearing at the cued location. The processing task may be a detection, localization or discrimination task. Two different types of cues have been found to modulate attentional orienting: centrally and peripherally presented cues (Posner \& Cohen, 1984). Central cues are symbolic signals which need to be semantically processed. Usually, they are also highly predictive about the target location (but see Hommel, Pratt, Colzato, \& Godijn, 2001; and Ho \& Spence, 2006). On the other hand, peripheral cues are salient stimuli, able to produce cuing effects even if they are uninformative signals about target location.

These two kinds of spatial cues produce different effects on the magnitude and time course of cuing effects (see Funes, Lupiáñez \& Milliken, 2005, and Corbetta \& Shulman, 2002, for recent reviews). Centrally presented cues generate a larger facilitation effect, which arises later than the facilitation effect produced by peripherally presented cues (Jonides \& Gleitman, 1976; Jonides, 1981; Müller \& Rabbitt, 1989; Hommel et al., 2001; Frischen \& Tipper, 2004). In addition, peripheral nonpredictive, but not central, cues also generate a negative cuing effect at long cue-target intervals (stimulus onset asynchrony or SOA), which is known as inhibition of return (IOR; Posner \& Cohen, 1984; Posner, Rafal, Choate, \& Vaughan, 1985).

Studies on the orientation of visuo-spatial attention have mostly used salient peripheral flashes and centrally presented arrows as cues. Nevertheless, other more complex types of cues have proven efficient too. Hommel et al. (2001) and Ho \& Spence (2006) used non-predictive direction words (i.e., the word "LEFT" written on the center of the screen), and found facilitatory effects on congruent spatial regions. Following up on the mental number line proposal (Dehaene, Bossini \& Giraux, 1993), Fischer, Castel, Dodd, \& Pratt (2003) found that numbers are also able to direct attention to the sides, small numbers facilitating targets presented on the left and large numbers facilitating targets on the right. These findings are very important for the purpose of our study, as they show that spatial attention can be directed on the basis of symbolic meaning even when the signal is nonpredictive and its relation to a location is mediated by a metaphorical mapping.

Furthermore, Weger \& Pratt (2008, Exp. 2a and 2b) already used a cuing paradigm to discriminate between spatial attention orienting and manual response codes activation when using future and past words as cues. The same experiment was carried out with two different groups: group A performed a discrimination task to a target presented to the left or right of the temporal word by pressing a left or right key, whereas group B performed a detection task to the same target by pressing the spacebar. They obtained a significant facilitation effect only for group A, what made them conclude that the effect obtained was due to a facilitation of response-codes. If the effect was of an attentional nature, they should have obtained a facilitation effect with group B as well.
However, we think that some methodological problems in their study might have lead to a nonsignificant cuing effect in group B. First, the authors recognized that the use of very few words (four past and four future words) repeated many times could result in semantic satiation (Smith \& Klein, 1990): a failure to access word semantics due to repetition. Second, the cue remained on screen during target presentation. The presence of another stimulus on the screen during target presentation could have interfered with the processing of the target. Third, the selection of participants did not seem to be strict enough. In their first experiment they used the name of past and present actors as cues. They had to eliminate 14 participants out of 34 from the analysis because they did not know who the actors were. This lack of knowledge was attributed to the multicultural origins of the participants. Recent experiments from our lab demonstrate that a careful control over the cultural origin of participants is very important because the facilitation effect obtained in a culture can take the opposite shape in another culture (Ouellet, Santiago, Israeli, \& Gabay, in press). These methodological problems could be responsible of their failure to observe a significant spatial attention orienting effect by means of temporal words. Alternatively, it might be the case that participants need to have activated an ego-centered reference point and the left-right horizontal axis, which is compulsory when participants have to respond with their left and right hands, but not when they use only one hand to press the space bar (Torralbo et al., 2006).

The present study aimed at investigating whether centrally written words with a temporal reference (inflected verbs and adverbs) can orient visuo-spatial attention in line with the left-past, rightfuture, horizontal spatial metaphor. Our second goal was to assess whether this mode of cuing is more coherent with typically central or peripheral cuing mechanisms. Our cues are centrally presented and need to be semantically processed, but they are also uninformative about target location and their meaning does not refer explicitly to target location. The three experiments reported hereby use a common paradigm in which a word's temporal meaning must be kept in working memory while cuing effects are tested on a localization task (Experiment 1) or a discrimination task (Experiments 2 and 3). According to Awh \& Jonides (2001), the maintenance in working memory of a given spatial location leads to the orienting of spatial attention towards such location, facilitating the processing of those stimuli appearing at the remembered location (see Awh \& Jonides, 2001; and Soto, Hodsoll, Rotshtein, \& Humphreys, 2008, for reviews on the relations between spatial attention and spatial working memory). In our first two experiments, a word is centrally presented and participants are asked to keep in mind its temporal reference (either past or future), as it will be probed at the end of the trial. Then, in Experiment 1, two empty squares at the left and right of the screen center are presented and a target stimulus is flashed in one of them. The participants must press a left or right key to indicate its position. Finally, the question "past?" or "future?" appears, and keypresses are now used to give a yes/no answer. Experiment 2 is similar to Experiment 1 except from the fact that a discrimination task with an embedded spatial Stroop procedure is used instead of the localization task. In this case, arrows are used as targets, and participants must press a left or right key to indicate arrow direction while ignoring arrow location. This task, contrary to a pure detection task, allowed us to study the influence exerted by temporal meanings on the orientation of visuo-spatial attention, while keeping 
activated the ego-centered reference point and horizontal axis. Experiment 3 uses the same spatial Stroop procedure as Experiment 2, with the following differences: the probe question at the end of each trial is replaced by a questionnaire at the end of the experiment (intended to reduce working memory load) and two different SOAs (one short and one long) are introduced in order to investigate the nature of the attentional orienting mechanism (Funes, Lupiáñez \& Milliken, 2005; Corbetta \& Shulman, 2002).

\section{Experiment 1}

The goal of the first experiment was to test whether processing and keeping in working memory the temporal reference of a word (past or future) is able to modulate processing in a concurrent left-right localization task.

\section{Procedure}

Participants. Twenty-seven undergraduate students from the University of Murcia and the University of Granada (mean age 19.48 years; 10 females and 17 males) participated for course credit. All of them were native Spanish speakers and reported to have normal or corrected-to-normal vision.

Materials. We used the same list of words as in Torralbo et al (2006): 24 Spanish words referring to past (e.g., "dijo" - "he said") and 24 referring to future (e.g., "dirá" - "he will say"). The word set comprised 18 verbs inflected in either past or future tense, and 6 past and 6 future temporal adverbs (e.g., "antes" - "before"). All words appeared in Courier New Bold font, point size 24. The task was programmed in E-prime (Schneider, Eschman, \& Zuccolotto, 2002) and ran in an Intel Pentium IV PC 1.70GHz. Stimuli were presented on a 15 -in. $(38.1-\mathrm{cm})$ color monitor. The target stimulus consisted of a dot of $5 \mathrm{~mm}$ diameter, which could appear in one of two $1.3 \times 1.3 \mathrm{~cm}$ boxes, presented at the center of the left and right halves of the screen $\left(7.39^{\circ}\right.$ of visual angle; 7.75 $\mathrm{cm}$ from the center). All stimuli were presented in white on a black background.

Procedure and design. Participants sat in a quiet room at approximately $60 \mathrm{~cm}$ from the screen. Trial structure was as follows. First, a fixation point was presented for $500 \mathrm{~ms}$, followed by a centrally presented word for $1,500 \mathrm{~ms}$, which could refer either to the past or to the future. Participants were instructed to memorize the temporal reference of the word. A blank screen followed during $500 \mathrm{~ms}$, and two empty squared boxes were presented at left and right positions. After $250 \mathrm{~ms}$, a white dot was flashed for $50 \mathrm{~ms}$ in one of the boxes. The two boxes remained on screen for 2,300 ms or until the participant responded. The participant pressed the " $z$ " key if the dot appeared to the left and the "m" key if it appeared to the right. After the localization task, a blank screen for 1,000 ms preceded one of two questions: “¿FUTURO?” ("FUTURE?”) or “PPASADO?” (“PAST?”). The question remained on the screen for $4,000 \mathrm{~ms}$ or until a response was recorded. Finally, there was a blank screen for 1,000 ms before the beginning of the next trial. Participants were asked to press the same " $z$ " or " $m$ " keys to indicate a yes or no response. They were not told about any possible relationship between the cue word and the target location or the target location and the final probe question.

The experiment had two blocks, differing in the mapping of " $\mathrm{z}$ " and " $m$ " to yes or no responses. The order of blocks was counter- balanced over participants. Within each block, each experimental word was presented four times, paired with targets at either location and with both final probe questions. Temporal reference of words was neither predictive of the target location nor predictive of the final probe question. Participants were allowed to take a break between blocks. Each block consisted of 16 practice and 192 experimental trials. The experiment lasted about 45-50 min.

\section{Results}

The data obtained from four participants were discarded because they failed to execute the task properly and the data from a further participant were lost due to technical problems. The results obtained from the remaining 22 participants are summarized in Table 1. Localization errors occurred on $1.42 \%$ of the trials $(120$ trials), and memory errors on $7.5 \%$ (634 trials). Trials with errors in any of the two tasks $(8.79 \%, 743$ trials) were excluded from the latency analysis. Correct trials with latencies below $100 \mathrm{~ms}$ and above $650 \mathrm{~ms}$ in the localization task (114 trials, 1.48\%) were considered outliers and also discarded.

Resulting latency and accuracy data were submitted to a 2 (Temporal Reference: past/future) $\times 2$ (Target Location: left/right) ANOVA taking both participants $(F 1)$ and items $(F 2)$ as random factors. Temporal Reference was a within-subject factor in the analysis by participants and a between-items factor in the analysis by items.

Accuracy data revealed no significant results (both main effects: $F$ s less than or near 1; Interaction: $F 1(1,21)=1.3, M S E=0.0001$, $p>.1 ; F 2(1,46)=1.701, M S E=0.0001, p>.1)$. In the latency analysis, Temporal Reference of the cue was not significant (both $F \mathrm{~s}<1)$ and the main effect of Target Location was significant only by items $(F 1<1 ; F 2(1,46)=20.04, M S E=36.06, p<$ $.001)$ : participants tended to respond faster to targets on the left. More important for the purpose of our study, we found a significant facilitation effect, indexed by an interaction between Temporal Reference and Target Location $(F 1(1,21)=11.22, M S E=$ $29.53 ; F 2(1,46)=8.82, M S E=36.06$, both $p \mathrm{~s}<0.01)$. Responding to left targets was $5 \mathrm{~ms}$ faster when the prime word referred to the past than when it referred to the future, and responding to right targets was $3 \mathrm{~ms}$ faster for future than past primes. Although small-sized, the effect was very systematic over participants and items, as suggested by the high $F$ values.

\section{Discussion}

The first experiment showed a left-past/right-future facilitation effect for targets presented at the location cued by the centrally presented temporal word. This suggests that temporal reference is

Table 1

Mean Latency and Percent Errors (in Parentheses) per Condition in Experiment 1 for the Factors Temporal Reference and Target Location

\begin{tabular}{lcc}
\hline Temporal reference & Past & Future \\
\hline Target location & & \\
Left & $260(1.3)$ & $265(1.1)$ \\
Right & $268(1.3)$ & $265(1.7)$ \\
\hline
\end{tabular}


able to orient attention along the left-right axis, thus biasing processing on a concurrent but completely unrelated localization task. However, given that left-right responses were correlated with left-right target locations, we cannot definitely dismiss the possibility that, instead of orienting attention, temporal meaning directly primes left or right response codes, as already shown by previous research (Santiago et al., 2007; Torralbo et al., 2006; Weger \& Pratt, 2008). Disentangling these two possibilities was the aim of Experiment 2.

\section{Experiment 2}

In order to dissociate purely attentional orienting from response priming as the factor underlying the left-right space-time congruency effect observed in Experiment 1, as well as in previous studies (Torralbo et al., 2006; Santiago et al., 2007), we replaced the localization task with a spatial Stroop task. Targets were arrows pointing either to the left or right, and participants were asked to respond with the key that matched the pointing direction of the arrow, independently of where the arrow was presented. By doing so, we were able to dissociate spatial attentional orienting and response priming as the underlying mechanisms for the effect observed in Experiment 1.

\section{Procedure}

Participants. Thirty-four undergraduate students (mean age 20.94 years; 30 females and 4 males) from the University of Granada participated for course credit. All of them were native Spanish speakers and reported to have normal or corrected-tonormal vision. None of them participated in the first experiment.

Materials. The same words as in Experiment 1 were used.

Procedure and design. The main difference between Experiments 1 and 2 was that the localization task was replaced by a spatial Stroop task. The two squared boxes were removed and the target dot was replaced by an arrow (13 $\mathrm{mm}$ in length, $12 \mathrm{~mm}$ in height), either pointing to the left or to the right. Arrow's location and pointing direction were completely orthogonal to the prime word's temporal reference. The participant's task was to indicate in which direction the arrow pointed to, by hitting the " $\mathrm{z}$ " keys if it pointed to the left and the " $\mathrm{m}$ " key if it pointed to the right. Words were presented four times each, matched with each of two target locations and two arrow-pointing directions. To avoid increasing the number of trials unnecessarily, the final probe questions were counterbalanced over participants.

\section{Results}

Participants failed to respond correctly on $3.75 \%$ of the trials (490 trials) in the Spatial Stroop task and on $7.83 \%$ of the trials $(1,022$ trials) in the memory task. Trials with one error in any of the two tasks $(11.17 \%, 1,459$ trials) were excluded from the latency analysis. Correct trials with latencies outside the 150- to 750-ms interval were considered outliers and excluded from the latency analysis, leading to a further rejection of $3.08 \%$ (357 trials) of data points.

An ANOVA was carried out to study the interaction between Temporal Reference (past-future), Target Location (left-right), and Response Side (left-right). Results are summarized in Table 2.
Table 2

Mean Latency and Percent Errors (in Parentheses) per

Condition in Experiment 2 for the Factors Target Location, Temporal Reference, and Response Side

\begin{tabular}{|c|c|c|c|c|}
\hline \multirow{2}{*}{\begin{tabular}{l}
\multicolumn{1}{c}{ Target location } \\
Temporal reference \\
Response side
\end{tabular}} & \multicolumn{2}{|c|}{ Left } & \multicolumn{2}{|c|}{ Right } \\
\hline & Past & Future & Past & Future \\
\hline Left & $372(0.9)$ & $378(0.9)$ & $434(7.5)$ & $432(6.1)$ \\
\hline Right & $421(7)$ & 419 (6.5) & $353(0.6)$ & $346(0.6)$ \\
\hline
\end{tabular}

Accuracy data showed that participants made fewer errors when Target Location was congruent with Response Side $(F 1(1,33)=$ 23.22, MSE $=0.0108, p<.001 ; F 2(1,46)=343.37, M S E=$ $0.0005, p<.001)$. The Temporal Reference of the words (past/ future) did not affect the distribution of errors $(F 1(1,33)=3$, $M S E=0.0006, p>.05 ; F 2(1,46)=2.31, M S E=0.0006, p>.1)$ and the three-way interaction between Temporal Reference, Target Location, and Response Side was not significant $(F 1(1,33)=2.91$, $M S E=0.0006, p>.05 ; F 2(1,46)=2.24, M S E=0.0005, p>.1)$. The $F 1$ and $F 2$ values of all the other factors and interactions were smaller than 1.

The latency analysis showed that participants were faster both responding with the right versus the left hand $(F 1(1,33)=18.54$, $M S E=1434.04, p<.001 ; F 2(1,46)=98.03, M S E=179.13, p<$ $.001)$, and to arrows presented on the right versus on the left side $(F 1(1,33)=8.47, M S E=309.32, p<.01 ; F 2(1,46)=13.33$, $M S E=122.17, p<.001)$. The main effect of Temporal Reference was not significant (both $F s<$ than 1). Latencies also showed a highly significant spatial Stroop effect, as indexed by a Target Location $\times$ Response Side interaction, $(F 1(1,33)=217.25$, $M S E=1282.79, p<.001 ; F 2(1,46)=1492.37, M S E=124.15$, $p<.001)$. Participants were faster responding to arrows pointing at a direction consistent with their position. Importantly for the goals of this analysis, the interaction between Temporal Reference and Response Side was significant by participants only $(F 1(1.33)=4.56, M S E=127.11, p<.05 ; F 2(1.46)=1.64$, $M S E=179.13, p>.1)$, and the interaction between Temporal Reference and Target Location was significant in both analyses $(F 1(1,33)=4.24, M S E=174.95, p<.05 ; F 2(1,46)=5.428$, $M S E=122.17, p<.05)$. Participants were faster both to identify targets and to respond to the left when the cue was a past word, and the opposite was true when the cue was a future word. There was no three-way interaction between the three factors (both $F_{\mathrm{s}}<1$ ).

\section{Discussion}

The results of the second experiment were clear-cut. First of all, there was a clear interaction between target location and pointing direction, indicating that we were able to replicate the spatial Stroop effect. Secondly, and more importantly for present goals, the temporal reference of the prime word interacted independently with response side (by participants) and target location (both by participants and items). The latter finding is very important because it supports the notion that the left-right past-future congruency effect in the present experiments and prior studies (Santiago et al, 2007; Torralbo et al., 2006) is not only based on the priming of manual response codes. Instead, temporal concepts seem to 
orient spatial attention, thus enhancing processing of spatially congruent targets.

\section{Experiment 3}

The main goal of the third experiment was to investigate in more detail the nature of the attentional orienting mechanism engaged by temporal word cues. To do so, we introduced one short and one long SOA. It is known that orientation of visual attention with central cues typically arises at long SOAs, whereas peripherally presented cues usually produce a facilitatory effect at short SOAs and an inverted effect at long SOAs (Funes, Lupiáñez \& Milliken, 2005; Corbetta \& Shulman, 2002). Experiments 1 and 2 did not study what happens at short SOAs, but the observed pattern of results was most consistent with temporal meaning orienting attention like central cues typically do. With the long cue-target SOA $(2,250 \mathrm{~ms})$ used, had the observed cuing effect been similar to peripheral cuing, IOR would have been a likely outcome (Posner \& Cohen, 1984; Posner et al., 1985). Therefore, we predicted a larger cuing effect at long SOAs, suggesting the use of an orienting mechanism similar to that activated by central cues. In order to reduce as much as possible experimental noise, we reduced working memory load by replacing the probe question at the end of each trial by a recognition phase at the end of the experiment, in which the participants had to identify the words presented during the experiment. Using a working memory task similar to ours, Han \& Kim (2008) observed that in the high working memory load condition, when their participants were asked to perform two distinct manual responses within a trial, the precision of the cuing effect decreased.

\section{Procedure}

Participants. Thirty-two undergraduate students (mean age 23.17 years; 23 females and 9 males) from the same population as in Experiment 2. None of them participated in prior experiments.

Materials. The same words as in Experiments 1 and 2 were used.

Procedure and design. Experiment 3 differed in some ways from Experiment 2. In order to be able to use a short SOA, we reduced cue presentation time to $300 \mathrm{~ms}$. One short and one long SOA were introduced by using two different interstimulus intervals (ISI), $250 \mathrm{~ms}$ for the short SOA and $800 \mathrm{~ms}$ for the long SOA. Short and long SOAs were randomly presented and completely orthogonal to the arrow's location and pointing direction and to the prime word's temporal reference. The participant was instructed at the beginning of the experiment to pay attention to the cue words because s/he would be asked at the end of the experiment to carry out a recognition test. Nothing was mentioned about the temporal reference of the cue words.

Words were presented eight times each, matched with each of two SOAs, two target locations, and two arrow-pointing directions. Experiment 3 doubled the number of trials, as compared to Experiments 1 and 2, but, because the probed question was removed, the experiment lasted approximately the same (more or less 50 $\min )$.

\section{Results}

Participants did not respond correctly on $3.1 \%$ of the trials (763 trials). Correct trials with latencies outside the 200- to $1,000-\mathrm{ms}$ interval were considered outliers and excluded from the latency analysis, leading to a further rejection of $1.44 \%$ (342 trials) of data points.

Resulting latency and accuracy data were submitted to a 2 (SOA: short/long) $\times 2$ (Temporal Reference: past/future) $\times 2$ (Target Location: left/right) $\times 2$ (Response Side: left/right) ANOVA taking both participants $(F 1)$ and items $(F 2)$ as random factors. Temporal Reference was a within-participants factor in the analysis by participants and a between-items factor in the analysis by items.

Accuracy data showed that participants tended to make fewer errors at short compared to long SOAs $(F 1(1,31)=2.05, M S E=$ $0.0012, p>.1 ; F 2(1,46)=4.64, M S E=0.0003, p<.05)$ [Table 3]. They were also more accurate responding at targets appearing to the right vs. to the left $(F 1(1,31)=3.45, M S E=$ $0.001, p=.073 ; F 2(1,46)=9.31, M S E=0.0003, p<.01)$. They also tended to respond better when the response was to the right compared to the left $(F 1<1 ; F 2(1,46)=3.27, M S E=0.0005$, $p=.077)$. More important for the purpose of our study, there was a highly significant congruency effect between Target Location and Response Side $(F 1(1,31)=24.54, M S E=0.0057, p=.001$; $F 2(1,46)=214.4, M S E=0.0005, p<.001)$, evidence that the spatial Stroop task worked as expected. The Temporal Reference main effect and all other interactions did not reach significance (with all Fs less than or near 1).

As in Experiment 2, latency analyses revealed a preference to the right compared to the left both at localizing targets $(F 1(1,31)=$ $5.14, M S E=759.18, p<.05 ; F 2(1,46)=25.87, M S E=160.65$, $p<.001)$, and responding to them $(F 1(1,31)=4.5, M S E=$ $3403.21, p<.05 ; F 2(1,46)=51.11, M S E=169.04, p<.001)$.

Table 3

Mean Latency and Percent Errors (in Parentheses) per Condition in Experiment 3 for the Factors SOA, Target Location, Temporal Reference, and Response Side

SOA

\begin{tabular}{|c|c|c|c|c|c|c|c|c|}
\hline \multirow[b]{2}{*}{ Target location } & \multicolumn{4}{|c|}{ Short } & \multicolumn{4}{|c|}{ Long } \\
\hline & \multicolumn{2}{|c|}{ Left } & \multicolumn{2}{|c|}{ Right } & \multicolumn{2}{|c|}{ Left } & \multicolumn{2}{|c|}{ Right } \\
\hline Temporal reference & Past & Future & Past & Future & Past & Future & Past & Future \\
\hline Left response side & $411(1.6)$ & $407(2.3)$ & $463(3.5)$ & $468(4.6)$ & $402(2.0)$ & $412(1.5)$ & $465(5.3)$ & $456(5.2)$ \\
\hline Right response side & $459(4.4)$ & $463(4.4)$ & $395(0.9)$ & $391(0.9)$ & $454(4.9)$ & $455(5.3)$ & $391(1.0)$ & $389(0.9)$ \\
\hline
\end{tabular}


There was a tendency for participants to respond faster at the long SOA $(F 1(1,31)=1.203, M S E=1860.28, p>.1 ; F 2(1,46)=$ $6.75, M S E=175.44, p<.05)$. The main effect of Temporal Reference was not significant (both $F s<1$ ). Latency analyses also showed a clear spatial Stroop effect $(F 1(1,31)=143.85, M S E=$ 3252.04, $p<.001 ; F 2(1,46)=1507.42, M S E=226.97, p<$ .001). Of a central interest, Temporal Reference again interacted with Target Location $(F 1(1,31)=4.61, M S E=230.86, p<.05$; $F 2(1,46)=4.01, M S E=160.65, p=.051)$ and this interaction was modulated by $\operatorname{SOA}(F 1(1,31)=5.69, M S E=174.54, p<$ $.05 ; F 2(1,46)=4.3, M S E=166.95, p<.05)$. Planned comparisons showed that the cuing past-left/future-right at the short SOA was not significant $(F 1$ and $F 2<1)$, whereas it was reliable at the long $\operatorname{SOA}(F 1(1,31)=9.79, M S E=210, p<.01 ; F 2(1,46)=$ 9.59, $M S E=141.87, p<.01)$. Surprisingly, Temporal Reference did not interact with Response Side, nor there was a significant three-way interaction among Temporal Reference, Response Side and Target Location (both $F s<1$ ). Finally, the latency analysis showed a significant four-way interaction $(F 1(1,31)=11.81$, $M S E=189.3, p<.01 ; F 2(1,46)=9.04, M S E=173.82, p<.01)$. This interaction was due to the fact that the Temporal Reference by Target Location interaction was modulated by SOA only for left-side responses $(F 1(1,31)=17.94, M S E=173.07, p<.001$; $F 2(1,46)=11.68, M S E=188.97, p<.01)$ but not for right-side responses $(F 1$ and $F 2<1)$.

\section{Discussion}

Experiment 3 confirmed that past and future words can orient visual attention towards left and right sides, respectively. This occurred under conditions which do not require the maintenance in working memory of temporal reference, but only the subsequent recognition of the presented words. Contrary to Experiment 2, the processing of Temporal Reference in Experiment 3 did not affect significantly the activation of congruent motor response codes. Torralbo et al. (2006) studied the flexibility of the conceptual projection of time onto space and their results demonstrated that the spatial frames of reference could be activated or not depending on their relevance for the task. It is possible that the spatial frame responsible for the Temporal Reference $\times$ Response Side interaction became less relevant for the task when participants were not asked anymore to manually respond to the cue at the end of each trial, thereby leading to a smaller influence of the temporal meaning of words on left-right response codes. In this case, as in Torralbo et al. (2006), the more relevant to the tasks visuo-spatial frame of reference was the only one affected. Although this interpretation remains as a post hoc speculation, the present pattern of results highlights the strength and consistency of the cuing effect on stimulus localization produced by the semantics of temporal words while the motor response activation effect seems to be weaker and can even fade out under some circumstances.

Moreover, the modulation of the Temporal Reference $\times$ Target Location interaction by SOA tells us more about the nature of the cuing effect. The cuing effect arose only at the longer SOA, as it is typically observed with the use of central cues. It is unclear why this effect was concentrated on left responses. One possibility is that the effect was enhanced with left responses because the level of difficulty was increased on the side contrary to the handedness of participants (only one of our participants was left handed).
Another possibility would be a spatial bias originated by the directionality of the orthographic system used by the participants. Spalek \& Hammad (2005) already observed a modulation of a well-known cuing effect (IOR) by the reading/writing direction of the participants. Left-to-right readers (English) showed a bigger IOR effect when previously cued on the left compared to the right, whereas it was the opposite with right-to-left readers (Arabic). Future research comparing left-to-right to right-to-left readers will permit to show whether or not the observed concentration on left responses is due to the direction of the orthographic system in use by the participants.

\section{General Discussion}

The first important finding of this study is that the temporal meaning of word cues orients spatial attention according to the space-time left-right conceptual metaphor. In contrast to prior studies (Santiago et al. 2007; Torralbo et al, 2006), participants did not respond directly to the prime words. Data were collected from responses to a target in a task orthogonal to the temporal concepts concurrently activated by the prime words. Nevertheless, the active temporal concept biased the processing of targets presented at locations consistent with a left-past right-future mental representation of time.

Secondly, and more importantly, the spatial Stroop discrimination task used in the second and third experiments allowed us to determine the nature of the influence of the lexical cue by dissociating between two possibilities: the orienting of visual attention vs. the activation of motor responses. In principle, the effect produced by the temporal words could result from a direct binding between the concepts of past and future to left and right responses (Pollmann \& Maertens, 2005). Núñez \& Sweetser (2006) showed that when we speak about the past we gesture to the left, whereas gestures referring to the future are directed towards the right. Consistently, the results of Experiment 2 showed that past/future meanings primed a motor response toward their congruent side. However, there was also a clear effect on the orientation of visuo-spatial attention produced by the semantics of temporal words: past cues produced a benefit for targets appearing on the left side, and future cues facilitated processing of targets appearing on the right side. These two effects were independent of each other. Contrary to Weger \& Pratt (2008), the results of Experiment 3 confirmed that the temporal meanings of past/future words could prime visual locations. It is still unclear whether or not an egocentered reference point needs to be activated, but present results strongly suggest that a purely attentional mechanism, based on a space-time mental line, contributes to explain left-right past-future congruency effects observed in present and previous studies.

Finally, the manipulation of SOA in Experiment 3 allowed us to peek into the nature of the underlying attentional mechanism. The cuing effect was larger at the longer SOA, therefore suggesting that temporal cues direct spatial attention by means of a typically central cuing mechanism (Funes, Lupiáñez, \& Milliken, 2005; Corbetta \& Shulman, 2002).

Having demonstrated an effect of attentional orienting after temporal cues, as we did not control for eye movements, we cannot be confident about whether temporal cues led to either covert or overt attentional orienting. Nevertheless, the type of analysis we used here offers clues to disentangle between sensory and motor 
activation effects. It has been demonstrated that saccade and manual responses share the same higher order spatial map (Briand, Larrison, \& Sereno, 2000; Khatoon, Briand, \& Sereno, 2002; Nemire, \& Bridgeman, 1987). Therefore, if the present cuing effect were due to overt orienting of attention, an interaction between temporal reference, target location and response location would have been a likely outcome (i.e., a faster response facilitation effect when the cue, the response and the target location are all in one direction, compared to when target location is incongruent with the cue and response). This was not the case. Moreover, if the orientation of the spatial attention produced by the temporal word cues would be arising at a motoric level, it would be difficult to explain how in Experiment 3 the cues did facilitate target localization but failed to facilitate congruent manual responses (motoric facilitation). For these reasons, we think that the present cuing effect is due to a covert attentional mechanism, although future research addressing directly this question is necessary before arriving to a firmer conclusion.

Present results hold important implications for both the nature of spatial attention and the mental representation of abstract concepts. They extend prior observations that meaning can be used to direct spatial attention (Hommel et al, 2001; and Ho \& Spence, 2006, with literal spatial words; and Fischer et al, 2003, with arabic numerals), and suggest that these conceptual cuing effects and the traditional central cues like arrows may engage a shared common attentional orienting mechanism. Moreover, the fact that Hommel et al (2001), Ho \& Spence (2006), and Fischer et al (2003), as well as the experiments reported herein, used nonpredictive cues casts doubt on the necessity of predictivity as a property of central cuing. More research is needed to establish the conditions under which a symbolic central cue needs or needs not to be predictive to exert an effect on attention.

Regarding the mental representation of abstract concepts, the present investigation supports the notion that at least some abstract concepts are represented by means of metaphorical mappings from more concrete, spatial domains. Although experimental scrutiny of this hypothesis has started only recently, the available evidence is growing steadily (e.g., Casasanto \& Boroditsky, 2008). Our results highlight the importance of not limiting the study of conceptual metaphors to those mappings attested in language (Casasanto, 2009), as the left-past/right-future metaphor is not present in linguistic expressions of any oral language (Radden, 2004, see the Introduction).

The domain of space seems to have a privileged role as a structural "donor" to many other conceptual domains (Gentner, Bowdle, Wolff, \& Boronat, 2001), but the available evidence only very rarely goes further than the mere test of psychological reality. With the exception of the number domain (see Fias \& Fischer, 2005), the present study is one of the first efforts to assess the underlying mechanisms which support abstract conceptual processing. Our main conclusion so far is that such mechanisms are surprisingly similar to those that are activated by literal words and symbols such as arrows.

\section{References}

Awh, E., \& Jonides, J. (2001). Overlapping mechanisms of attention and spatial working memory. Trends in Cognitive Sciences, 5, 119-126.

Briand, K. A., Larrison, A. L., \& Sereno, A. B. (2000). Inhibition of return in manual and saccadic response systems. Perception and Psychophysics, 62, 1512-1524.

Casasanto, D. (2009). When is a linguistic metaphor a conceptual metaphor? In V. Evans \& S. Pourcel (Eds.), New Directions in Cognitive Linguistics. Amsterdam: John Benjamins.

Casasanto, D., \& Boroditsky, L. (2008). Time in the mind: Using space to think about time. Cognition, 106, 579-593.

Corbetta, M., \& Shulman, G. L. (2002). Control of goal-directed and stimulus-driven attention in the brain. Nature Reviews Neuroscience, 3, 201-215.

Dehaene, S., Bossini, S., \& Giraux, P. (1993). The mental representation of parity and number magnitude. Journal of Experimental Psychology: General, 122, 371-396.

Fias, W., \& Fischer, M. H. (2005). Spatial representation of numbers. In J. I. D. Campbell (ed.), Handbook of Mathematical Cognition (pp. 43-54). Hove: Psychology Press.

Fischer, M. H., Castel, A. D., Dodd, M. D., \& Pratt, J. (2003). Perceiving numbers causes spatial shifts of attention. Nature Neuroscience, 6 , $555-556$.

Frischen, A., \& Tipper, S. P. (2004). Orienting attention via observed gaze shifts evokes longer-term inhibitory effects: Implications for social interactions, attention and memory. Journal of Experimental Psychology: General, 133, 516-533.

Funes, M. J., Lupiáñez, J., \& Milliken, B. (2005). The role of spatial attention and other processes on the magnitude and time course of cueing effects. Cognitive Processing, 6, 98-116.

Gentner, D., Bowdle, B., Wolff, P., \& Boronat, C. (2001). Metaphor is like analogy. In D. Gentner, K. Holyoak, and B. N. Kokinov (Eds.), The analogical mind: Perspectives from cognitive science (pp. 199-253). Cambridge, MA: MIT Press.

Han, S. W., \& Kim, M. S. (2008). Spatial working memory load impairs signal enhancement, but not attentional orienting. Attention, Perception, and Psychophysics, 70, 916-923.

Haspelmath, M. (1997). From space to time: Temporal adverbials in the world's languages. Newcastle, UK: Lincom Europa.

Ho, C., \& Spence, C. (2006). Verbal interface design: Do verbal directional cues automatically orient visual spatial attention? Computers in Human Behavior, 22, 733-748.

Hommel, B., Pratt, J., Colzato, L., \& Godijn, R. (2001). Symbolic control of visual attention. Psychological Science, 12, 360-365.

Johnson, M. (1987). The body in the mind. Chicago: University of Chicago Press.

Jonides, J. (1981). Voluntary versus automatic control over the mind's eye's movement. In J. Long \& A. Baddeley (Eds.), Attention and performance IX (pp. 187-203). Hillsdale, NJ: Erlbaum.

Jonides, J., \& Gleitman, H. (1976). The benefit of categorization in visual search: Target location without identification. Perception and Psychophysics, 20, 289-298.

Khatoon, S., Briand, K. A., \& Sereno, A. B. (2002). The role of response in spatial attention: Direct versus indirect stimulus-response mappings. Vision Research, 42, 2693-2708.

Lakoff, G., \& Johnson, M. (1980). Metaphors we live by. Chicago: University of Chicago Press.

Lakoff, G., \& Johnson, M. (1999). Philosophy in the flesh: The embodied mind and its challenge to Western thought. New York: Basic Books.

Müller, H. J., \& Rabbitt, P. M. A. (1989). Reflexive and voluntary orienting of visual attention: Time course of activation and resistance to interruption. Journal of Experimental Psychology: Human Perception and Performance, 15, 315-330.

Nemire, K., \& Bridgeman, B. (1987). Oculomotor and skeletal motor systems share one map of visual space. Vision Research, 27, 393-400.

Núñez, R., \& Sweetser, E. (2006). With the future behind them: Convergent evidence from Aymara language and gesture in the crosslinguistic comparison of spatial construals of time. Cognitive Science, 30, 1-49. 
Ouellet, M., Santiago, J., Israeli, Z., \& Gabay, S. (in press). Is the future the right time? Experimental Psychology. doi: 10.1027/1618-3169/a000036

Pollmann, S., \& Maertens, M. (2005). Shift of activity from attention to motor-related brain areas during visual learning. Nature Neuroscience, 8, 1494-1496.

Posner, M. I. (1980). Orienting of attention. Quarterly Journal of Experimental Psychology, 32, 3-25.

Posner, M. I., \& Cohen, Y. (1984). Components of visual orienting. In H. Bouma \& D. Bowhuis (Eds.), Attention and performance X (pp. 531556). Hillsdale, NJ: Erlbaum.

Posner, M. I., Nissen, M., \& Ogden, W. (1978). Attended and unattended processing modes: The role of set for spatial location. In H. L. Pick \& E. Saltzman (Eds.), Modes of perceiving and processing information (pp. 128-181). Hillsdale, NJ: Erlbaum.

Posner, M. I., Rafal, R. D., Choate, L. S., \& Vaughan, J. (1985). Inhibition of return: Neural basis and function. Cognitive Neuropsychology, 2, 211-228.

Radden, G. (2004). The metaphor TIME AS SPACE across languages. In: N. Baumgarten, C. Böttger, M. Motz, \& J. Probst (Eds.) Uebersetzen, interkulturelle Kommunikation, Spracherwerb und Sprachvermittlung das Leben mit mehreren sprachen: Festschrift fuer Juliane House zum 60. Geburtstag pp. 226-239. Bochum: Aks-verlag.

Santiago, J., Lupiáñez, J., Pérez, E., \& Funes, M. J. (2007). Time (also) flies from left to right. Psychonomic Bulletin and Review, 14, 512-516.

Santiago, J., Román, A., Ouellet, M., Rodríguez, N., \& Pérez-Azor, P.
(2008). In hindsight, life flows from left to right. Psychological Research. doi: 10.1007/s00426-008-0220-0

Schneider, W., Eschman, A., \& Zuccolotto, A. (2002). E-Prime user's guide. Pittsburgh, PA: Psychology Software Tools Inc.

Smith, L., \& Klein, R. (1990). Evidence of semantic satiation: Repeating a category slows subsequent semantic processing. Journal of Experimental Psychology: Learning, Memory, and Cognition, 16, 852-861.

Soto, D., Hodsoll, J., Rotshtein, P., \& Humphreys, G. W. (2008). Automatic guidance of attention from working memory. Trends in Cognitive Sciences, 12, 342-348.

Spalek, T. M., \& Hammad, S. (2005). The left-to-right bias in inhibition of return is due to the direction of reading. Psychological Science, 16, 15-18.

Torralbo, A., Santiago, J., \& Lupiáñez, J. (2006). Flexible conceptual projection of time onto spatial frames of reference. Cognitive Science, 30, 745-757.

Tversky, B., Kugelmass, S., \& Winter, A. (1991). Cross-cultural and developmental trends in graphic productions. Cognitive Psychology, 23, 515-557.

Weger, U., \& Pratt, J. (2008). Time flies like an arrow: Space-time compatibility effects suggest the use of a mental time-line. Psychonomic Bulletin and Review, 15, 426-430.

Received February 28, 2008 Revision received April 1, 2009

Accepted May 15, 2009

\section{Low Publication Prices for APA Members and Affiliates}

Keeping you up-to-date. All APA Fellows, Members, Associates, and Student Affiliates receive-as part of their annual dues-subscriptions to the American Psychologist and APA Monitor. High School Teacher and International Affiliates receive subscriptions to the APA Monitor, and they may subscribe to the American Psychologist at a significantly reduced rate. In addition, all Members and Student Affiliates are eligible for savings of up to $60 \%$ (plus a journal credit) on all other APA journals, as well as significant discounts on subscriptions from cooperating societies and publishers (e.g., the American Association for Counseling and Development, Academic Press, and Human Sciences Press).

Essential resources. APA members and affiliates receive special rates for purchases of APA books, including the Publication Manual of the American Psychological Association, and on dozens of new topical books each year.

Other benefits of membership. Membership in APA also provides eligibility for competitive insurance plans, continuing education programs, reduced APA convention fees, and specialty divisions.

More information. Write to American Psychological Association, Membership Services, 750 First Street, NE, Washington, DC 20002-4242. 